\title{
Correlation between koilocytes and human papillomavirus detection by PCR in oral and oropharynx squamous cell carcinoma biopsies
}

\author{
Glauco Issamu Miyahara ${ }^{+}$, Luciana Estevam Simonato, Neivio José Mattar, \\ Deolino João Camilo Jr, Eder Ricardo Biasoli \\ Departamento de Patologia e Propedêutica, Centro de Oncologia Bucal, Faculdade de Odontologia de Araçatuba, \\ Universidade Estadual Paulista, Araçatuba, SP, Brasil
}

The purpose of this study was to compare the histopathological analysis with polymerase chain reaction (PCR) methods to predict the presence of human papillomavirus (HPV) infection in oral squamous cell carcinoma biopsies. Eighty-three paraffin-embedded tissue specimens from patients with oropharynx and mouth floor squamous cell carcinoma were submitted to histopathological analysis under light microscopy, specifically for the determination of the presence of koilocytes. Subsequently, DNA was purified from the same paraffin-embedded specimens and submitted to PCR. Fisher's exact test showed no statistically significant correlation between the two methods. The results suggest that the presence of koilocytes is unreliable for the detection of HPV presence in oral and oropharynx squamous cell carcinoma.

Key words: human papillomavirus - squamous cell carcinoma - microscopy - polymerase chain reaction

Human papillomavirus (HPV) is considered to be an etiological factor for uterine cervix carcinoma and its association with oral and oropharyngeal carcinomas has recently been addressed. More than 130-200 HPV types have already been described (Lajer \& von Buchwald 2010). Non-oncogenic HPV types 6 and 11 induce epithelial proliferations, such as papillomas and condylomas. On the other hand, the oncogenic HPV types 16 and 18 are associated with carcinomas and are capable of transforming epithelial cells of the genital and respiratory tracts (Villa 2007). Epidemiological studies have stated that HPV plays an important role in the development of oral and oropharyngeal lesions (D'Souza et al. 2007). Whether the new HPV vaccines will protect against cervical cancer and HPV-positive head and neck squamous cell carcinoma remains unknown (Lajer \& von Buchwald 2010). A possible involvement of HPV in the development of precancerous lesions and oral carcinoma was first proposed by Syrjänen et al. (1983); based on light microscopy examination, they observed cytopathic HPV alterations (koilocytosis) in 35\% of the oral squamous cell carcinoma biopsies that were identical to those found in precancerous lesions and uterine cervix carcinoma.

The histological diagnosis is based on HPV-related histopathological aspects, such as koilocytosis, dyskeratosis, papillomatosis, hyperkeratosis, acanthosis and parakeratosis. Koilocytosis is the most common cytopathic effect and is considered by pathologists to be the major histopathological aspect for determination of

\footnotetext{
Financial support: FAPESP, PROINTER (UNESP)

+ Corresponding author: miyahara@foa.unesp.br

Received 20 August 2010

Accepted 24 November 2010
}

HPV infection. Koilocytosis consists of the presence of abnormal koilocytes that are vacuolated with nuclear pyknosis and large clear perinuclear halos that usually occupy a greater volume than that of the cytoplasm. It is considered a pathognomonic sign of HPV-associated lesions (Fornatora et al. 1996). While some authors suggested an association between cytological and immunohistochemical positivity for HPV (Löning et al. 1987), others found no morphological aspects that confirm the presence of HPV by polymerase chain reaction (PCR) (Salvia et al. 2004). Histopathological analysis under light microscopy is the most commonly used method for oral pathology diagnosis and it is a useful method for the observation of viral particles when molecular biology methods are not available. To compare the histopathological diagnosis with PCR methods and to predict the presence of HPV infection, a retrospective analysis was conducted on 83 paraffin-embedded tissue specimens that were obtained from patients with a histopathological diagnosis of oropharynx or mouth floor squamous cell carcinoma. The specimens were retrieved from the archives of the Oral Oncology Center at the School of Dentistry of Araçatuba [approved by the Human Research Ethics Committee at the São Paulo State University (2006-00931)]. For this study, 4- $\mu$ m-thick sections obtained from the paraffin-embedded squamous cell carcinoma samples were stained with hematoxylin and eosin. Histopathological diagnoses of oropharynx or mouth floor squamous cell carcinoma were provided by two pathologists. No cases of verrucous carcinoma or other lesions were included in this study. The pathologists were not aware of the PCR HPV test results. For DNA extraction and PCR analysis, $10-\mu \mathrm{m}$-thick histological sections obtained from the same paraffin-embedded squamous cell carcinoma samples were used. Histological sections were transferred to $1.5 \mathrm{~mL}$ sterile RNase, DNase, DNA-free microcentrifuge tubes until 
$25 \mathrm{mg}$ of each sample was obtained, which was then deparaffinized and rehydrated. A QIAamp DNA Mini Kit (Qiagen $\mathrm{GmbH}$, Hilden, Germany) was used according to the manufacturer's instructions for DNA extraction and the samples were stored at $-20^{\circ} \mathrm{C}$. Initially, PCR was performed for the identification of the DNA fragments from the human beta-globin gene (256 bp), using primers GH20 (5'-GAAGAGCCAAGGACAGGTAC-3) and PC04 (5'-CAACTTCATCCACGTTC ACC-3) to confirm the presence and integrity of the DNA collected in the paraffin-embedded samples. The analysis was performed by polyacrylamide gel electrophoresis using an EP3501 electrophoresis apparatus (Amersham Pharmacia Biotech, Sweden) for $2 \mathrm{~h}$ at $100 \mathrm{~V}, 500 \mathrm{~mA}$ and $100 \mathrm{~W}$ (Fig. 1). After confirmation of DNA integrity, HPV detection was performed by nested PCR using the universally accepted consensus external primers, MY11 (5'-GCMCAGGGWCTATAAYAATGG-3') and MY09 (5'-CTCCMARRGGAWACTGATC-3'); the internal primers, GP5+ (5'-TTTGTTACTGTGGTAGATACYAC-3') and GP6+ (5'-GAAAAATAAACTTGT AAATCATATTC-3'). These primers were used for the amplification of $150 \mathrm{bp}$ fragments of HPV DNA. The reactions were carried out in a programmable-temperature DNA thermal cycler (PTC-100; Peltier-Effect Cycling, MJ Research, Waltham, USA) using initial denaturation at $95^{\circ} \mathrm{C}$ for $5 \mathrm{~min}$, followed by 38 cycles of denaturation at $95^{\circ} \mathrm{C}$ for $1 \mathrm{~min}$, annealing at $40^{\circ} \mathrm{C}$ for $2 \mathrm{~min}$, elongation at $72^{\circ} \mathrm{C}$ for $90 \mathrm{~s}$ and a final elongation at $72^{\circ} \mathrm{C}$ for $8 \mathrm{~min}$.
Statistical analysis of the data was performed using the Epi Info 2000 software (Centers for Disease Control and Prevention, Atlanta, GA, USA). A Fisher's exact test was used to compare the cases of squamous cell carcinoma that exhibited histopathological aspects suggestive of HPV infection with the presence of HPV DNA confirmed by PCR. Significance level was set at 5\% for all analyses.

Koilocytosis was the most frequent histopathological aspect suggestive of HPV infection and was observed in $37.3 \%$ (31/83) (Fig. 1) of the total analyzed oral squamous cell carcinoma biopsies $(\mathrm{n}=83)$. Viral DNA amplification by PCR was detected in 33.7\% (28/83) of the cases (Fig. 2). Analysis of the data by a Fisher's exact test showed no statistically significant correlation $(\mathrm{p}=$ 0.3069 ) between the presence of histopathological aspects suggestive of HPV infection and the presence of HPV DNA confirmed by PCR (Table).

The prevalence of HPV in the oral cavity varies widely depending on the method of detection and the location of the lesion. A previous study that correlated histopathological findings in cervix carcinoma biopsies with PCR-based HPV detection reported that the most common aspects of HPV presence were koilocytosis $(88.89 \%)$ and binucleation (75\%). Although koilocytosis denotes an important morphological marker for HPV infection, it is not a precise basis for HPV diagnosis because it results in approximately $30 \%$ false-positives, which should be considered (Salvia et al. 2004). In the present study, of 55 cases of negative PCR-based HPV
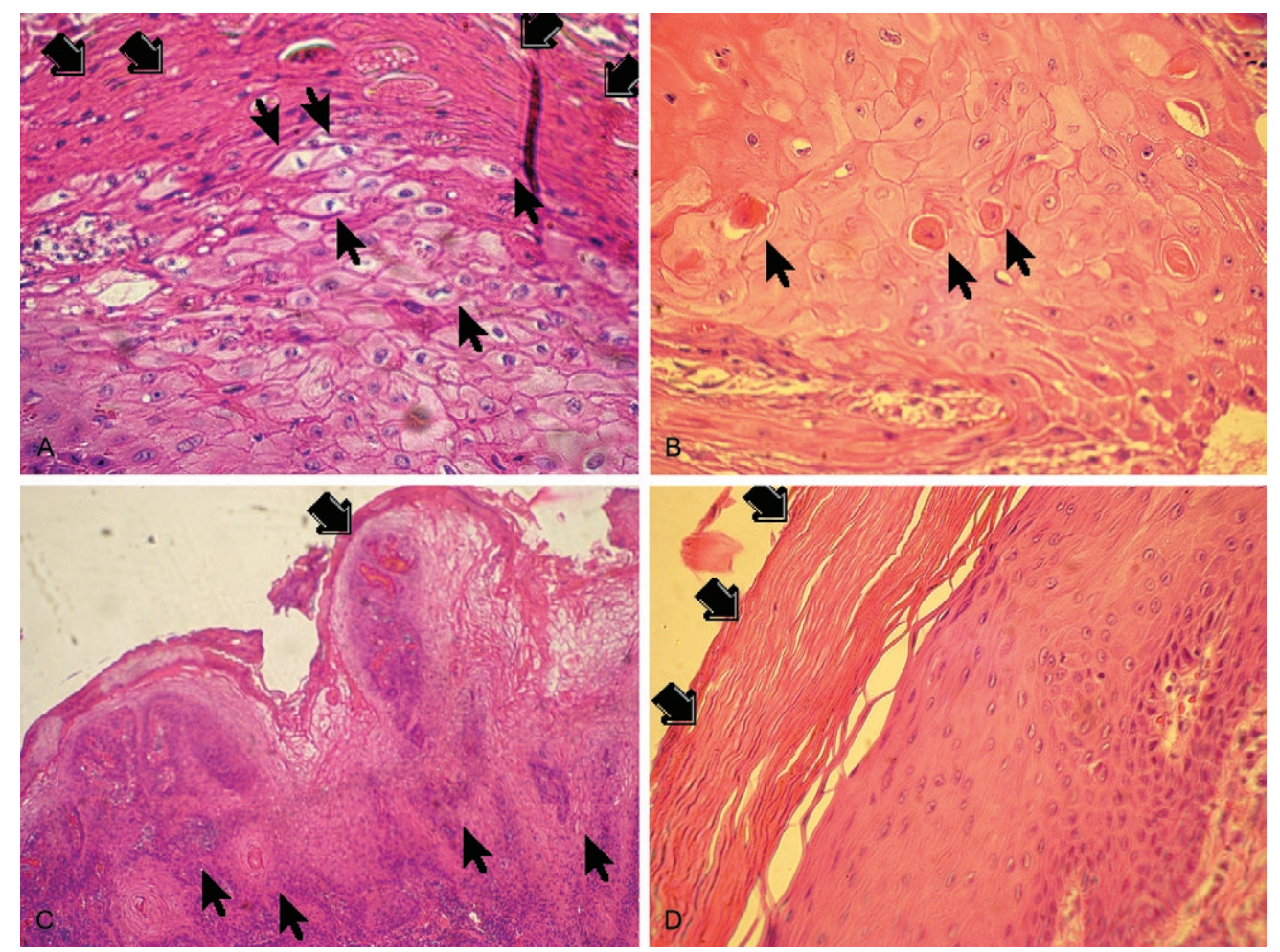

Fig. 1A: koilocytosis (thin arrows); parakeratosis (large arrows). Hematoxylin and eosin (H\&E) 200X; B: dyskeratosis (arrows). H\&E: 200X; C: papillomatosis (large arrow) and acanthosis (thin arrows). H\&E: 100X; D: hyperkeratosis (arrows). H\&E: 100X. 

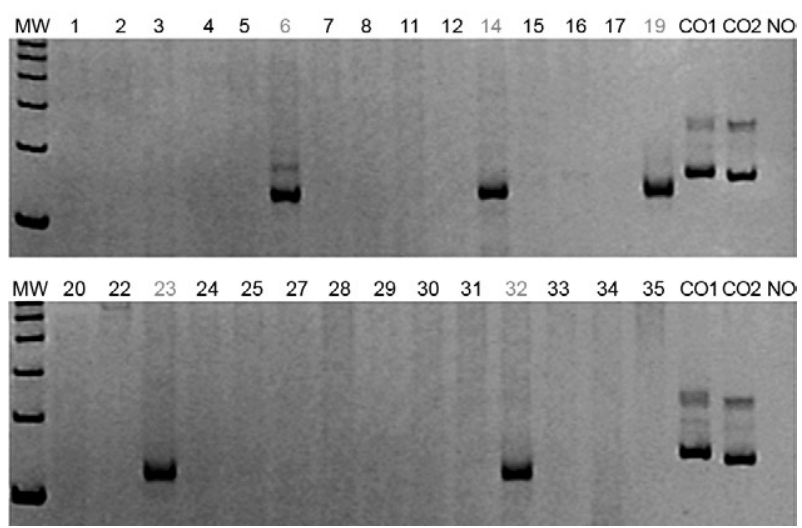

Fig. 2: polyacrylamide gel electrophoresis $(8 \%)$ representing nested polymerase chain reaction results of samples of squamous cell carcinoma. $\mathrm{CO} 1=$ positive control 1 (HeLa DNA); $\mathrm{CO} 2=$ positive control 2 (condyloma DNA); MW: molecular weight marker (100 bp); NO: negative control (without DNA).

\section{TABLE}

Correlation between the morphological criteria suggestive of human papillomavirus (HPV) (koilocytosis) and the presence of HPV confirmed by polymerase chain reaction (PCR) in the squamous cell carcinoma biopsies examined in this study

\begin{tabular}{llccc}
\hline & & Absent & Present & Total \\
\hline Koilocytosis $^{a}$ & PCR positive & 16 & 12 & 28 \\
& PCR negative & 36 & 19 & 55 \\
\hline
\end{tabular}

$a$ : Fisher $(\mathrm{p}=0.3069)$.

detection, koilocytosis occurred in 19 cases (34.5\%). On the other hand, $12(42.8 \%)$ of 28 samples with positive PCR-based HPV detection showed the presence of koilocytosis. These findings are similar to those of Löning et al. (1987), who studied a series of 22 squamous cell carcinomas of the oral cavity, pharynx and larynx and four oral leukoplakias without dysplasia by conventional light microscopy and dot blot hybridization for the detection of HPV DNA. Koilocytosis was observed in 10 of 22 carcinomas and three of four oral leukoplakias. HPV DNA was found in eight of 22 carcinomas; in six of these eight cases, severe koilocytosis was observed.

Traditionally, the cytological diagnosis of HPV infection is also based on the identification of dyskeratosis, which is the second most important cytopathic effect suggestive of HPV presence. It often occurs along with koilocytosis. All these alterations should be considered as indicators of a possible viral infection (Löning et al. 1987, Fornatora et al. 1996); however, koilocytosis seems to be the most important pathognomonic sign of HPV presence as described by some authors (Krawczyk et al. 2008, Aggarwal et al. 2009).

While clinical examination and biopsy provide information on the characteristics of HPV-suggestive lesions,
PCR and hybrid capture-based HPV detection systems identify all HPV types and are more sensitive methods (Zuna et al. 2006). Al-Qahtani et al. (2007) conducted a retrospective study of 199 patients with oral squamous cell carcinoma followed by a review of the histopathological sections of 146 available cases. The authors found positive PCR-based HPV detection in only one sample. Because HPV was negative in approximately $99.3 \%$ of the samples, it could not be stated that histopathological aspects are pathognomonic features of the presence of HPV, which is consistent with our results.

HPV presence has an important role in the carcinogenesis of oral squamous cell carcinoma, especially in the oropharynx; however, HPV DNA presence is observed in both benign and malignant lesions (Al-Qahtani et al. 2007, Termine et al. 2008). To establish a lesion pattern, only oropharynx and mouth floor squamous cell carcinoma were included in this study. One metaanalysis study observed that the prevalence of HPV was higher in carcinomas of the oropharynx (38.1\%) than in carcinomas of the mouth, pharynx and larynx (24.1\%) (Termine et al. 2008). Conversely, in our study, HPV prevalence was higher (33.7\%) and more consistent with data from mouth, pharynx and larynx squamous cell carcinoma (34.5\%) studies that used PCR methods, as reported in a recent review by Campisi et al. (2007). The use of fresh tissue will increase the detection rate due to better quality of DNA material, but paraffin-embedded materials allow for retrospective study.

In conclusion, our results suggest that in HPV infections, the presence of koilocytes in oral and oropharyngeal squamous cell carcinoma biopsies does not accurately indicate viral infection.

\section{ACKNOWLEDGEMENTS}

To Maria LMM Sundefeld, for the statistical analysis.

\section{REFERENCES}

Aggarwal S, Arora VK, Gupta S, Singh N, Bhatia A 2009. Koilocytosis: correlations with high-risk HPV and its comparison on tissue sections and cytology, urothelial carcinoma. Diagn Cytopathol 37: 174-177.

Al-Qahtani K, Brousseau V, Paczesny D, Domanowski G, Hamid Q, Hier M, Black M, Franco E, Kost K 2007. Koilocytosis in oral squamous cell carcinoma: what does it mean? J Otolaryngol 36: 26-31.

Campisi G, Panzarella V, Giuliani M, Lajolo C, Di Fede O, Falaschini S, Di Liberto C, Scully C, Lo Muzio L 2007. Human papillomavirus: its identity and controversial role in oral oncogenesis, premalignant and malignant lesions (review). Int J Oncol 30: 813-823.

D’Souza G, Kreimer AR, Viscidi R, Pawlita M, Fakhry C, Koch WM, Westra WH, Gillison ML 2007. Case-control study of human papillomavirus and oropharyngeal cancer. N Engl J Med 356: 1944-1956.

Fornatora M, Jones AC, Kerpel S, Freedman P 1996. Human papillomavirus-associated oral epithelial dysplasia (koilicytic dysplasia): an entity of unknown biologic potential. Oral Surg Oral Med Oral Pathol Oral Radiol Endod 82: 47-56.

Krawczyk E, Suprynowicz FA, Liu X, Dai Y, Hartmann DP, Hanover J, Schlegel R 2008. Koilocytosis: a cooperative interaction between the human papillomavirus E5 and E6 oncoproteins. Am J Pathol 173: 682-688. 
Lajer CB, von Buchwald C 2010. The role of human papillomavirus in head and neck cancer. APMIS 118: 510-519.

Löning T, Meichsner M, Milde-Langosch K, Hinze H, Orlt I, Hörmann K, Sesterhenn K, Becker J, Reichart P 1987. HPV DNA detection in tumours of the head and neck: a comparative light microscopy and DNA hybridization study. ORL J Otorhinolaryngol Relat Spec 49: 259-269.

Salvia PN, Bergo SM, Bonesso-Sabadini PI, Tagliarini EB, Hackel C, De Angelo Andrade LA 2004. Correlation between histological criteria and human papillomavirus presence based on PCR assay in cervical biopsies. Int J Gynecol Cancer 14: 126-132.

Syrjänen K, Syrjänen S, Lamberg M, Pyrhönen S, Nuutinen J 1983.
Morphological and immunohistochemical evidence suggesting human papillomavirus (HPV) involvement in oral squamous cell carcinogenesis. Int J Oral Surg 12: 418-424.

Termine N, Panzarella V, Falaschini S, Russo A, Matranga D, Lo Muzio L, Campisi G 2008. HPV in oral squamous cell carcinoma vs. head and neck squamous cell carcinoma biopsies: a metaanalysis (1988-2007). Ann Oncol 19: 1681-1690.

Villa LL 2007. Overview of the clinical development and results of a quadrivalent HPV (types 6, 11, 16, 18) vaccine. Int J Infect Dis 11 (Suppl. 2): S17-S25.

Zuna RE, Wang SS, Schiffman M, Solomon D 2006. Comparison of human papillomavirus distribution in cytologic subgroups of low-grade squamous intraepithelial lesion. Cancer 108: 288-297. 